\title{
Influence of angiographic spontaneous coronary reperfusion on long-term prognosis in patients with ST-segment elevation myocardial infarction
}

\author{
Xiaoming $\mathrm{Li}^{1,{ }^{*}}$, Boyu $\mathrm{Li}^{1,{ }^{*}}$, Jing Gao ${ }^{1, *}$, Yunfei Wang ${ }^{1}$, Song Xue ${ }^{1}$, Dachuan Jiang ${ }^{1}$, Qi Hua ${ }^{1}$ \\ and Jing $\mathbf{L i}^{1}$ \\ ${ }^{1}$ Division of Cardiology, Xuanwu Hospital Capital Medical University, Beijing, China \\ *These authors contributed equally to this work and share co-first authors \\ Correspondence to: Jing Li, email: shpxbb@sina.com \\ Qi Hua, email: huaqi5371@medmail.com.cn
}

Keywords: ST-segment elevation myocardial infarction, spontaneous reperfusion, coronary angiography, prognosis

Received: April 05, 2017

Accepted: June 30, 2017

Published: July 18, 2017

Copyright: Li et al. This is an open-access article distributed under the terms of the Creative Commons Attribution License 3.0 (CC BY 3.0), which permits unrestricted use, distribution, and reproduction in any medium, provided the original author and source are credited.

\section{ABSTRACT}

Objective: To explore the influence of angiographic spontaneous coronary reperfusion (SR) on the short- and long-term outcomes in patients with ST-segment elevation myocardial infarction (STEMI).

Materials and Methods: Consecutive patients diagnosed as STEMI and undergoing emergent coronary angiography from January 2009 to August 2010 in a single center were enrolled. Patients whose initial coronary blood flow met Thrombolysis in Myocardial Infarction (TIMI) grade 3 were regarded as angiographic SR. Others (TIMI grade $<3$ ) were included into the NSR group and subsequently underwent primary percutaneous coronary intervention (PCI). Patients' characteristics and outcomes were compared.

Results: A total of 207 patients were eligible for analysis. The coincidence rate of patients both with $\geq 70 \%$ ST-segment resolution and $\geq 70 \%$ relief of chest pain and SR was $100 \%$. Patients in the SR group $(n=38)$ were younger, had more smokers, with higher level of platelet count, lower blood glucose and uric acid, and more distal culprit lesions, as compared to the NSR group $(n=169)$. Importantly, patients in the SR group had lower rates of in-hospital events ( 0 vs. $22.5 \%, p<0.001$ ) with less stents placed $(1.03 \pm 1.05$ vs. $1.59 \pm 1.17, p=0.007)$. Moreover, there were comparable long-term outcomes $(2.6 \%$ vs. $6.9 \%, p=0.302)$ between the two groups during 41-month follow ups.

Conclusions: Angiographic SR is associated with significantly favorable shortterm outcomes.

\section{INTRODUCTION}

Reperfusion strategy, including fibrinolytic therapy or primary percutaneous coronary intervention (PCI), is the key point to reduce mortality in ST-segment elevation myocardial infarction (STEMI). In daily practice, it is not rare that some patients may achieve reopening of the culprit artery without undergoing any reperfusion therapy, which is termed as spontaneous reperfusion (SR).

In previous studies, SR was defined as initial coronary flow of Thrombolysis in Myocardial Infarction (TIMI)
[1] grade 3 assessed by emergent angiography [2-4]. Frequency of SR varies around 10\%-30\% [5-9]. Compared to non-SR (NSR) patients, SR is associated with a lower rate of short-term mortality or heart failure $[2-5,7,9]$. However, the relationship between SR and patient characteristics is still unclear. Moreover, fewer studies have reported the influence of SR on treatment strategy or long-term outcomes.

In the current study, we collected patients diagnosed with STEMI and tried to investigate the relation between clinical features and SR. We also explore the relationship 
of ST segment resolution and symptom relief and SR. Moreover, in-hospital events and long-term outcomes were compared between SR patients and NSR patients.

\section{MATERIALS AND METHODS}

\section{Study population}

In this retrospective study, STEMI patients, who had chest pain within $12 \mathrm{~h}$ and underwent emergency coronary angiography in one medical center from January 2009 to August 2010, were included. Exclusion criteria: 1) patients received thrombolytic therapy; 2) patients had prior myocardial infarction; 3) Patients refused angiography. Patients were divided into SR group and NSR group. SR referred to the culprit vessel achieved coronary blood flow of TIMI grade 3 identified by initial angiogram.

All patients received $300 \mathrm{mg}$ of aspirin loading dose and $300 \mathrm{mg}$ of clopidogrel, followed by $100 \mathrm{mg}$ of aspirin maintenance dose and $75 \mathrm{mg}$ of clopidogrel per day. Patient characteristics and in-hospital events were collected by questionnaires or medical records. Inhospital events referred to composite of any-cause death, reinfarction, congestive heart failure and cardiogenic shock [10]. Reinfarction was identified as an acute myocardial infarction occurred during the time of in the hospital after an incident myocardial infarction. Reinfarction was considered when ST elevation $\geq 0.1 \mathrm{mV}$ recurs, or new pathognomonic $Q$ waves appear, in at least two contiguous leads, particularly when associated with ischaemic symptoms for $20 \mathrm{~min}$ or longer. If the cTn concentration is elevated, but stable or decreasing at the time of suspected reinfarction, the diagnosis of reinfarction requires a $20 \%$ or greater increase of the cTn value in the second sample. If the initial cTn concentration is normal, the criteria for new acute myocardial infarction apply [11]. All biochemistry indexes were tested in the center laboratory within 24 hours.

\section{Diagnostic criteria for STEMI}

If following criteria were present: the presence of continuous chest pain lasting $\geq 20$ minutes; and either 1 ) ST-segment elevation of $\geq 2 \mathrm{~mm}$ in at least 2 contiguous precordial leads, or 2) ST-segment elevation of $\geq 1 \mathrm{~mm}$ in at least 2 inferior leads, or 3) new left bundle branch block [11]. It was later confirmed by the elevation of myocardial biomarker (CK-MB or troponin) $\geq 2$ folds of normal value.

\section{Chest pain assessment}

Chest pain was assessed with a numerical rating scale (NRS). Patients were asked to rate their pain on an 11-point scale, where 0 indicated no pain and 10 indicated the worst imaginable pain [12] at the admission (emergency room or at home). Reduction in pain for each patient was inquired before initiation of emergency coronary angiography. Symptom relief was defined as above $50 \%$ easement of pain as compared to the top level of pain for each patient.

\section{ST segment resolution assessment}

Electrocardiograms were examined at the admission and initiation of emergency coronary angiography. ST segment resolution was defined as $50-100 \%$ reduction in sum ST elevation.

\section{Coronary angiography}

Coronary angiography was performed using 5-6 French Judkins catheters through femoral or radial approaches [13]. The decision to perform PCI was made based on the discretion of operators. Usually, if patients in the SR group had significant stenosis in the target vessel or other vessels, we preferred to perform an elective PCI after 7 days of the initial angiography.

\section{Long-term follow up}

Follow up information was collected via phone call every 6 months. Primary endpoint was defined as major adverse cardiovascular and cerebrovascular events (MACCE), referring to composite of any-cause death, non-fatal cardiac arrest, acute coronary syndrome, congestive heart failure and stroke [14]. If any event occurred, primary endpoint was reached. This study was approved by the ethics committee of the hospital and the informed consents were obtained from patients. All authors have approved the manuscript and we confirm that all methods were performed in accordance with the relevant guidelines and regulations. The full disclosure of any potential conflict of interest has been declared.

\section{Statistical analysis}

Continuous variables are presented as mean \pm SD or if not normally distributed as median with interquartile range. Two-sample $t$-tests or rank-sum tests were used to test group differences. For categorical variables, the data were summarized in percentages and $\mathrm{X}^{2}$ or Fisher exact test was used to assess group differences, where appropriate. Multivariate logistic regression analysis was performed to estimate odds ratios (OR) and 95\% confidence intervals $(95 \% \mathrm{CI})$ to identify independent predictors of SR. Long-term survival of MACCE was estimated with the Kaplan-Meier method. The Cox proportional hazard survival model was used to assess the association between SR and long-term outcomes while adjusting for potential confounders. A value of $p<0.05$ was considered significant. All tests were two-sided, with a 5\% level of significance. All analyses were performed using SPSS software 13.0 (SPSS Inc; Chicago, IL, USA). 


\section{RESULTS}

\section{Baseline characteristics}

A total of 207 patients were eligible for analysis. Among them, 38 (18.4\%) met the criteria of SR. Study flowchart is shown in Figure 1. In the NSR group, 130 (76.9\%) patients got a TIMI flow grade 3 after emergent PCI. Patients in the SR group were younger $(56.76 \pm 12.89$ vs. $61.80 \pm 11.78, p=0.020)$ and more smokers $(73.7 \%$ vs. $53.3 \%, p=0.022)$. The platelet $\left(266.64 \pm 66.91 \times 10^{9} / \mathrm{L}\right.$ vs. $234.49 \pm 66.86 \times 10^{9} / \mathrm{L}, p=0.010$ ), blood level of uric acid $(298.03 \pm 74.46 \times \mu \mathrm{mol} / \mathrm{L}$ vs. $340.47 \pm 106.89 \times \mu \mathrm{mol} / \mathrm{L}$, $p=0.025)$ and glucose $(6.04 \times \mathrm{mmol} / \mathrm{L}$ vs. $7.98 \times \mathrm{mmol} / \mathrm{L}$, $p=0.005)$ levels were statistically different between SR and NSR group (Table 1).

In the SR group, 22 (57.9\%) patients had severe $(\geq 90 \%)$ stenosis in culprit artery, while $10(26.3 \%)$ patients with stenosis about $80-89 \%, 2(5.3 \%)$ with stenosis about $70-79 \%$ and $4(10.5 \%)$ with $<70 \%$ stenosis.

The culprit lesions were more distal in the SR group than those in the NSR group $(26.3 \%$ vs. $9.5 \%, p<0.005)$. Stents were placed in $4(10.5 \%)$ patients of the SR group and $143(84.6 \%)$ of the NSR group during the initial procedure $(p<0.001)$ (Table 2). Number of stents placed in emergent procedure was far less in the SR group than that of the NSR group $(0.18 \pm 0.61$ vs. $1.16 \pm 0.70, p$ $<0.001$ ). After emergent and selective PCI, patients in the SR group still had a lower rate of stent placement than the NSR group $(60.5 \%$ vs. $86.4 \%, p=0.020)$ (Table 2). The total number of stents used for treating culprit lesions in the SR group was less than that in the NSR group $(1.03 \pm 1.05$ vs. $1.59 \pm 1.17, p=0.007)$ (Table 2$)$.

\section{Clinical predictors for SR}

The coincidence rate of patients both with $\geq 70 \%$ ST-segment resolution and $\geq 70 \%$ relief of chest pain and SR was $100 \%$.

\section{Factors related to $\mathrm{SR}$}

Multiple variable analysis showed platelet (OR, 1.007; 95\% CI: 1.001-1.013; $p=0.019$ ), blood glucose (OR, 0.750; 95\% CI: $0.622-0.905 ; p=0.003$ ), uric acid (OR, 0.993; 95\% CI: 0.800-0.998; $p=0.011$ ), and culprit

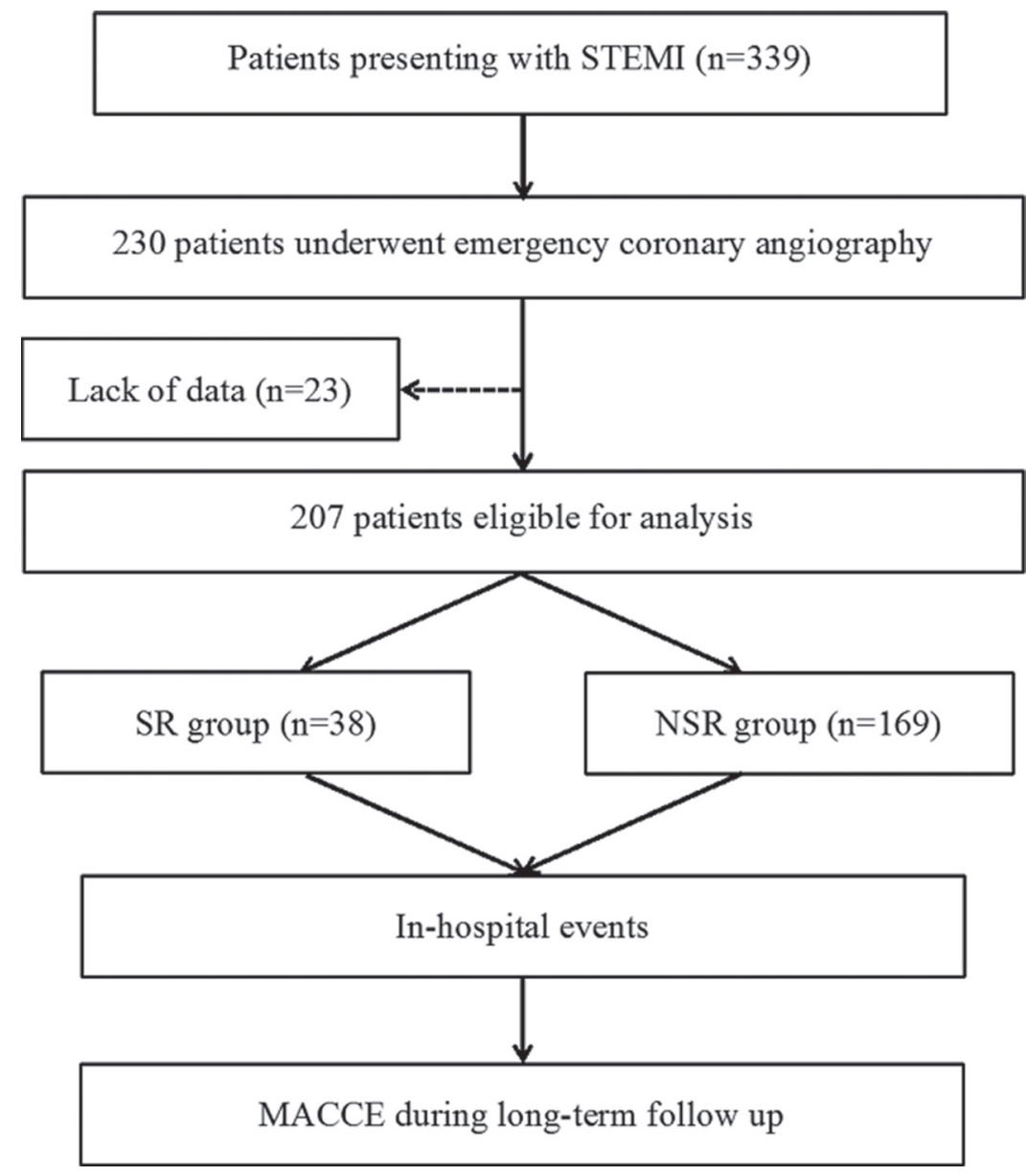

Figure 1: Flow chart of the study. MACCE = major and adverse cardiovascular and cerebrovascular events; NSR = non-spontaneous reperfusion; SR = spontaneous reperfusion; STEMI = ST-segment elevation myocardial infarction. 


\begin{tabular}{|c|c|c|c|}
\hline & SR Group & NSR Group & \multirow{2}{*}{$\boldsymbol{P}$} \\
\hline & $(n=38)$ & $(n=169)$ & \\
\hline Age (years) & $56.76 \pm 12.89$ & $61.80 \pm 11.78$ & 0.020 \\
\hline Gender (Male/Female) & $34 / 4$ & $131 / 38$ & 0.098 \\
\hline Hypertension $(\%)$ & $18(47.4)$ & $85(50.3)$ & 0.744 \\
\hline Diabetes mellitus $(\%)$ & $8(21.1)$ & $39(23.1)$ & 0.788 \\
\hline Smoking $(\%)$ & $28(73.7)$ & $98(53.3)$ & 0.022 \\
\hline Anterior wall myocardial infarction (\%) & $22(57.9)$ & $69(40.8)$ & 0.055 \\
\hline Systolic blood pressure (mm Hg) [median (Q1, Q3)] & $134(112-147)$ & $135(112-146)$ & 0.451 \\
\hline Diastolic blood pressure (mm Hg) [median (Q1, Q3)] & $79(70-86)$ & $78(66-88)$ & 0.761 \\
\hline Heart rate (/min) [median $(\mathrm{Q} 1, \mathrm{Q} 3)]$ & $78(67-86)$ & $75(63-88)$ & 0.288 \\
\hline Time from symptom onset $(\mathrm{h})$ [median $(\mathrm{Q} 1, \mathrm{Q} 3)]$ & $4.9(2.4-6)$ & $4.5(2.5-5)$ & 0.505 \\
\hline $\mathrm{EF}(\%)$ & $59 \pm 9$ & $56 \pm 10$ & 0.126 \\
\hline Time from symptom onset to PCI (min) [median (Q1, Q3)] & $195(175-365)$ & $347(210-395)$ & 0.419 \\
\hline Killip cardiac functional grading I-II (\%) & $36(94.7)$ & $162(95.9)$ & 0.759 \\
\hline GP IIb/IIIa antagonist before procedures ( $\%)$ & $3(14.3)$ & $9(8.6)$ & 0.398 \\
\hline \multicolumn{4}{|l|}{ Admission drug treatment } \\
\hline Aspirin $(\%)$ & $38(100)$ & $159(94.1)$ & 0.124 \\
\hline Clopidogrel (\%) & $38(100)$ & $158(93.5)$ & 0.106 \\
\hline Beta-blockers $(\%)$ & $33(86.8)$ & $123(76.8)$ & 0.069 \\
\hline ACE inhibitors (\%) & $37(97.4)$ & $146(86.45)$ & 0.056 \\
\hline Nitrates $(\%)$ & $36(94.7)$ & $141(83.49)$ & 0.267 \\
\hline Low-molecular-weight heparins $(\%)$ & $38(100)$ & $167(98.8)$ & 0.438 \\
\hline Platelet $\left(10^{9} / \mathrm{L}\right)$ & $266.64 \pm 66.91$ & $234.49 \pm 66.86$ & 0.010 \\
\hline Blood glucose $(\mathrm{mmol} / \mathrm{L})$ & $6.04(4.30-7.36)$ & $7.98(5.65-8.77)$ & $<0.001$ \\
\hline Uric acid $(\mu \mathrm{mol} / \mathrm{L})$ & $298.03 \pm 74.46$ & $340.47 \pm 106.89$ & 0.025 \\
\hline High density lipoprotein $(\mathrm{mmol} / \mathrm{L})$ & $1.04 \pm 0.19$ & $1.06 \pm 0.24$ & 0.687 \\
\hline Low density lipoprotein (mmol/L) & $2.62 \pm 0.81$ & $2.62 \pm 0.80$ & 0.982 \\
\hline Serum creatinine $(\mathrm{mol} / \mathrm{L})[$ median $(\mathrm{Q} 1, \mathrm{Q} 3)]$ & $69.1(61.0-77.8)$ & $76.9(60.0-82.0)$ & 0.507 \\
\hline
\end{tabular}

Data are presented as percentage or median (25th, 75th centile), Q1 $=25$ th quartiles, Q3 $=75$ th quartiles, where appropriate. $\mathrm{ACE}=$ angiotensin converting enzyme, $\mathrm{EF}=$ ejection fraction, GP = Glycoprotein, NSR = non-spontaneous reperfusion, $\mathrm{PCI}=$ percutaneous coronary intervention, $\mathrm{SR}=$ spontaneous reperfusion.

lesion in distal lesions (OR, 0.107; 95\% CI: 0.029-0.393; $p=0.001)$ or left anterior descending branch (LAD) (OR, 0.285; 95\% CI: 0.105-0.711; $p=0.013$ ) were independently associated with SR (Table 3 ).

\section{In-hospital events}

Patients in the SR group had a significantly lower rate of in-hospital events as compared to the NSR group, including total events ( 0 vs. $22.5 \%, p<0.001$ ), any-cause death ( 0 vs. $5.9 \%)$, reinfarction ( 0 vs. $3.0 \%)$, congestive heart failure (0 vs. $7.1 \%)$ and cardiogenic shock (0 vs. $6.5 \%$ ). The in-hospital mortality of the SR group had no statistically significant difference compared to those in the NSR group ( $0 \%$ vs. $5.9 \%, p=0.125)$.

\section{Long-term outcome}

A total of 197 patients were enrolled in the follow up of the study. Median duration of the follow up was 41 months (Quartile 1: 37 months and Quartile 3: 45 months). The longest follow up was 53 months. There were $16(8.1 \%)$ patients lost follow-up (4 patients in the SR group and 16 patients in the NSR group, $10.5 \%$ vs. $7.5 \%, p=0.546$ ). Patients in the SR group had a non-statistically lower rate of MACCE as compared to the NSR group $(2.6 \%$ vs. $6.9 \%, p=0.302)$ (Figure 2$)$. Age (OR, 1.077; 95\% CI: 1.014-1.143; $p=0.016$ ) and hypertension (OR, 5.201, 95\% CI: 1.134-23.855; $p=0.034)$ were independent predictors of long-term events (Table 4). 


\begin{tabular}{lccc}
\hline & $\begin{array}{c}\text { SR Group } \\
(\boldsymbol{n}=\mathbf{3 8})\end{array}$ & $\begin{array}{c}\text { NSR Group } \\
(\boldsymbol{n}=\mathbf{1 6 9})\end{array}$ & $\boldsymbol{P}$ \\
\hline Infarct-related artery & & & 0.024 \\
LAD (\%) & $21(55.3)$ & $71(42.0)$ & \\
LCX (\%) & $9(23.7)$ & $23(13.6)$ & \\
RCA (\%) & $8(21.1)$ & $75(44.4)$ & 0.233 \\
Infarct-related artery was LAD (\%) & $21(55.3)$ & $71(42.0)$ & 0.005 \\
Distal lesions (\%) & $10(26.3)$ & $16(9.5)$ & 0.510 \\
Vessel disease & & & \\
One-vessel disease (\%) & $18(47.4)$ & $74(43.8)$ & \\
Two-vessel disease (\%) & $12(31.6)$ & $44(26.0)$ & $<0.001$ \\
Three-vessel disease (\%) & $8(21.1)$ & $51(30.2)$ & 0.001 \\
Number of stents placed in emergent procedure & $0.18 \pm 0.61$ & $1.16 \pm 0.70$ & 0.007 \\
Emergent stent placement & $4(10.5)$ & $143(84.6)$ & 0.020 \\
Total number of stents placed & $1.03 \pm 1.05$ & $1.59 \pm 1.17$ & 0.545 \\
Patients undergoing PCI (\%) & $23(60.5)$ & $146(86.4)$ & 0.740 \\
Stent diameter (mm) & $3.44 \pm 0.36$ & $3.38 \pm 0.45$ & $45.5 \pm 28.0$ \\
Total stent length (mm) & $42.3 \pm 18.4$ & & \\
\hline
\end{tabular}

$\mathrm{LAD}=$ left anterior descending branch, $\mathrm{LCX}=$ left circumflex artery, NSR $=$ non-spontaneous reperfusion, $\mathrm{RCA}=$ right coronary artery, $\mathrm{PCI}=$ percutaneous coronary Intervention, $\mathrm{SR}=$ spontaneous reperfusion.

Table 3: Factors related to spontaneous reperfusion

\begin{tabular}{lccc}
\hline & B & OR $(\mathbf{9 5} \% \mathbf{C I})$ & $\boldsymbol{P}$ \\
\hline Age (years) & -0.012 & $0.988(0.945-1.033)$ & 0.592 \\
Gender & 0.550 & $1.733(0.391-7.682)$ & 0.469 \\
EF $(\%)$ & 0.010 & $1.011(0.600-1.060)$ & 0.677 \\
Infarct-related artery was LAD & -1.256 & $0.285(0.105-0.711)$ & 0.013 \\
Distal lesions & -2.239 & $0.107(0.029-0.393)$ & 0.001 \\
Platelet $\left(10^{9} / \mathrm{L}\right)$ & 0.007 & $1.007(1.001-1.013)$ & 0.019 \\
Neutrophils $\left(10^{9} / \mathrm{L}\right)$ & -0.030 & $0.970(0.833-1.130)$ & 0.698 \\
Blood glucose $(\mathrm{mmol} / \mathrm{L})$ & -0.287 & $0.750(0.622-0.905)$ & 0.003 \\
Uric acid $(\mu \mathrm{mol} / \mathrm{L})$ & -0.007 & $0.993(0.800-0.998)$ & 0.011 \\
High density lipoprotein $(\mathrm{mmol} / \mathrm{L})$ & -0.696 & $0.499(0.046-5.459)$ & 0.569 \\
Low density lipoprotein $(\mathrm{mmol} / \mathrm{L})$ & 0.244 & $1.277(0.711-2.291)$ & 0.413 \\
Serum creatinine $(\mathrm{mol} / \mathrm{L})$ & 0.005 & $1.001(0.962-1.062)$ & 0.662 \\
\hline
\end{tabular}

$\mathrm{CI}=$ confidence interval. $\mathrm{EF}=$ eiection fraction. $\mathrm{LAD}=$ left anterior descending branch. $\mathrm{OR}=$ Odds ratio.

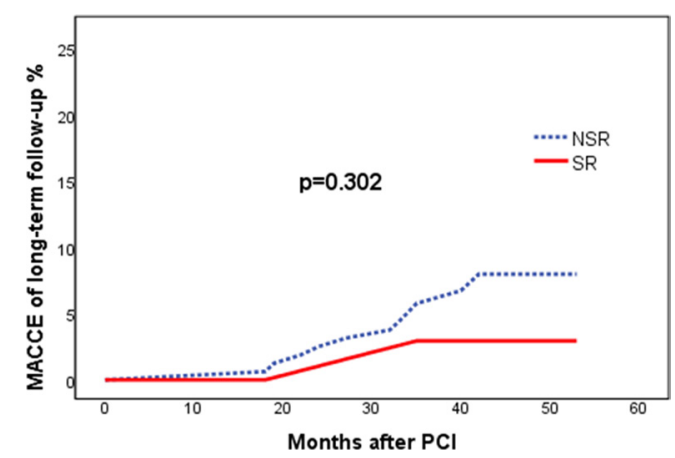

Figure 2: Kaplan-Meier curves for major and adverse cardiovascular and cerebrovascular events. MACCE = major and adverse cardiovascular and cerebrovascular events; NSR = non-spontaneous reperfusion; PCI = percutaneous coronary intervention; SR = spontaneous reperfusion. 
Table 4: Cox proportional hazards regression of long-term clinical outcomes

\begin{tabular}{lcc}
\hline & OR (95\% CI) & $P$ \\
\hline Age (years) & $1.077(1.014-1.143)$ & 0.016 \\
Gender & $1.960(0.563-6.823)$ & 0.291 \\
Hypertension & $5.201(1.134-23.855)$ & 0.034 \\
Diabetes mellitus & $0.714(0.171-2.977)$ & 0.644 \\
Smoking & $1.112(0.277-4.456)$ & 0.881 \\
SR & $0.232(0.032-1.669)$ & 0.304 \\
Killip cardiac functional grading I-II & $0.147(0.064-0.381)$ & 0.147 \\
\hline
\end{tabular}

$\mathrm{CI}=$ confidence interval, $\mathrm{OR}=$ Odds ratio, $\mathrm{SR}=$ spontaneous reperfusion .

Table 5: Cox proportional hazards regression of long-term clinical outcomes after excluding patients with slow blood flow

\begin{tabular}{lcc}
\hline & OR $\mathbf{( 9 5 \%}$ CI) & $\boldsymbol{P}$ \\
\hline Age (years) & $1.095(1.024-1.171)$ & 0.008 \\
Gender & $1.405(0.335-5.899)$ & 0.642 \\
Hypertension & $5.818(1.214-27.878)$ & 0.028 \\
Diabetes mellitus & $0.188(0.022-1.650)$ & 0.132 \\
Smoking & $0.773(0.188-3.173)$ & 0.721 \\
SR & $0.522(0.062-4.365)$ & 0.548 \\
Killip cardiac functional grading I-II & $0.629(0.173-2.278)$ & 0.480 \\
\hline
\end{tabular}

$\mathrm{CI}=$ confidence interval, $\mathrm{OR}=$ Odds ratio, $\mathrm{SR}=$ spontaneous reperfusion.

As $23.1 \%$ of patients in the NSR group did not achieve blood flow of TIMI grade 3 finally, which may attribute to poor outcomes. We therefore analyzed the data again after excluding patients with slow blood flow. Eventually, patients in the SR $(n=38)$ group still had a lower rate of in-hospital events ( 0 vs. $16.9 \%, p=0.007)$ compared to the NSR $(n=130)$ group and the two groups had the similar long-term outcomes $(2.6 \%$ vs. $6.3 \%$, $p=0.378)$. Age (OR, 1.095; 95\% CI: 1.024-1.171; $p=0.008)$ and hypertension (OR, 5.818, 95\% CI: 1.214 $27.878 ; p=0.028)$ were independent predictors of longterm events (Table 5).

\section{DISCUSSION}

In this study, we found the incidence of SR was $18.4 \%$. Combination of $\geq 70 \%$ ST-segment resolution with $\geq 70 \%$ of relief in pain could clinically predict SR with high accuracy. Platelet count, lower levels of blood glucose and uric acid, distal lesions and LAD as infarctrelated artery (IRA) were independently associated with SR. More importantly, SR may result in lower rate of inhospital events despite less stent placement.

Previous studies [6-8] have suggested that STEMI patients with SR had improved left ventricular function, lower incidence of congestive heart failure and decreased short-term mortality, as compared to patients without SR. In the current study, we also indicated significantly better in-hospital outcome among patients with SR. The possible mechanism could be: 1) SR may be associated with earlier opening time in occluded arteries, resulting in smaller myocardial infarct size. 2) In our study, $23.1 \%$ of patients in the NSR group did not achieve blood flow of TIMI grade 3, which may result in poor outcomes. Furthermore, when we only compared patients having TIMI grade 3, SR was still associated with lower in-hospital events. We therefore speculate that the SR group might have more effective reperfusion not only by the reopening of epicardial arteries but also in the microcirculatory level, as compared to patients in the NSR group. 3) Our data demonstrated that stent placement could be safely deferred in the patients with SR. The SR group had a lower rate of stent placement $(10.5 \%$ vs. $84.6 \%$ in emergent procedure and $60.5 \%$ vs. $86.4 \%$ totally) which might be associated with less procedure-related complications as compared to NSR group. Future studies are needed to confirm our speculations regarding the mechanism of benefit associated with SR.

Although SR was associated with favorable inhospital events, but no significantly difference was verified with regarding to the long-term follow up. The MACCE were $2.6 \%$ in SR group and $6.9 \%$ in NSR group, which were relatively lower compared to previous studies [15]. This may somewhat reflect the improvement on management of STEMI and therefore diminish the gap on prognosis between the two groups. Moreover, patient amount was relatively small in the current study, which may impair the power of statistical analysis.

In fibrinolytic era, complete resolution of ST segment elevation, early peaking of biomarkers, 
reperfusion arrhythmias and relief of chest pain, has been investigated for noninvasive assessment of TIMI grade 3 after thrombolytic therapy, indicating patency of the culprit vessel [16-18]. Even so, clinical features are still considered to be poor markers of reperfusion, without any combinations of them being more able to predictive coronary artery patency more reliably [19]. In our study, when ST segment resolution $\geq 70 \%$ and symptom relief $\geq 70 \%$ were combined to predict SR, the coincidence rate of patients both with $\geq 70 \%$ ST-segment resolution and $\geq 70 \%$ relief of chest pain and SR was $100 \%$. Thus, it may be feasible for physicians to accurately identify the restoration of coronary blood flow in patients with STEMI, based on those clinical features.

Since endogenous fibrinolysis or pretreatment with anti-thrombotic agents is regarded to be conducive to SR [2], some clinical characteristics may be associated with SR. Rimar D [10], et al. found the incidence of SR was $4 \%$ of STEMI patients, and old age, preinfarction angina, hypertension, non-Q wave myocardial infarction, and Killip class I on admission were independent variables associated with SR. However, Stone GW [2], et al. indicated the rate of SR is $16 \%$ but no baseline characteristics clearly predicted SR. In this study, we founded that higher level of uric acid and blood glucose were independently related to SR. Akpek M [20], et al. reported uric acid had a negative relation with TIMI blood flow in STEMI patients undergoing primary PCI. Timmer JR [21], et al. showed hyperglycemia could predict an initial TIMI flow grade 0 to 2 before primary PCI in STEMI patients. Theoretically, uric acid may promote activation of clotting factors, inhibit natural anticoagulant and lead to mural thrombosis through inflammation or platelet pathway, therefore inhibit thrombus autolysis [22-23]. Hyperglycemia could increase activation platelet, damage endothelium-dependent vasodilation and increased inflammatory responses, finally affect platelet function, blood coagulation and fibrinolysis, leading to thrombosis hard to dissolve [24-25]. Interestingly, our data showed patients in SR group had lower platelet levels compared to NSR group. We speculate that these patients may have more severe platelet consumption due to higher thrombotic burden in the culprit lesion. Further studies are needed to elucidate the mechanism.

\section{Study limitations}

Limitations of the study include that all data were collected from one institution which may leave selection bias. Moreover, we could not identify the exact duration between coronary blockage and reopening in SR patients. Also, we did not have data about peak levels of CK-MB or troponin to represent and compare the myocardial damage between the SR and NSR groups. Additionally, we speculated that less PCIs might be associated less procedure-related complications, which may partly account for the favorable outcome in the SR group.
However, no consolidate data supported it. Further studies are needed to confirm this point. Finally, this study could not reflect influence of new anti-thrombosis agents on SR.

\section{CONCLUSIONS}

Spontaneous reperfusion is not rare daily practice. $\mathrm{SR}$ is associated with favorable outcomes, despite of less stent usage. Stent placement could be safely deferred in the patients with SR.

\section{CONFLICTS OF INTEREST}

There were no potential conflicts of interest.

\section{FUNDING}

This study was supported by the grant 81470491 from the National Natural Science Foundation of China to Dr. Li.

\section{REFERENCES}

1. Chesebro JH, Knatterud G, Roberts R, Borer J, Cohen LS, Dalen J, Dodge HT, Francis CK, Hillis D, Ludbrook P, Markis JE, Mueller H, Passamani ER, et al. Thrombolysis in Myocardial Infarction (TIMI) Trial, Phase I: a comparison between intravenous tissue plasminogen activator and intravenous streptokinase. Clinical findings through hospital discharge. Circulation. 1987; 76:142-54.

2. Stone GW, Cox D, Garcia E, Brodie BR, Morice MC, Griffin J, Mattos L, Lansky AJ, O'Neill WW, Grines CL. Normal flow (TIMI-3) before mechanical reperfusion therapy is an independent determinant of survival in acute myocardial infarction: analysis from the primary angioplasty in myocardial infarction trials. Circulation. 2001; 104:636-41.

3. Cannon CP. Importance of TIMI 3 flow. Circulation. 2001; 104:624-6.

4. Lekston A, Hudzik B, Szkodziński J, Gasior M, Tajstra M, Kalarus Z, Szyguła-Jurkiewicz B, Poloński L. Spontaneous reperfusion before intervention improves immediate but not long-term prognosis in diabetic patients with ST-segment elevation myocardial infarction and multivessel coronary artery disease. Cardiol J. 2013; 20:378-84.

5. Fefer P, Hod H, Hammerman H, Boyko V, Behar S, Matetzky S. Relation of clinically defined spontaneous reperfusion to outcome in ST-elevation myocardial infarction. Am J Cardiol. 2009; 103:149-53.

6. Erden EC, Erden I, Türker Y, Aslantaş Y, Yalçın S, Karabacak A. Amount of ST wave resolution in patients with and without spontaneous coronary reperfusion in the infarct-related artery after primary PCI: an observational study. Anadolu Kardiyol Derg. 2012; 12:30-4.

7. Terkelsen CJ, Kaltoft AK, Nørgaard BL, Bøttcher M, Lassen JF, Clausen K, Nielsen SS, Thuesen L, Nielsen TT, 
Bøtker HE, Andersen HR. ST changes before and during primary percutaneous coronary intervention predict final infarct size in patients with ST elevation myocardial infarction. J Electrocardiol. 2009; 42:64-72.

8. Bainey KR, Fu Y, Wagner GS, Goodman SG, Ross A, Granger CB, Van de Werf F, Armstrong PW; ASSENT 4 PCI Investigators. Spontaneous reperfusion in ST-elevation myocardial infarction: comparison of angiographic and electrocardiographic assessments. Am Heart J. 2008; 156:248-55.

9. Leibowitz D, Gerganski P, Nowatzky J, Weiss AT, Rott D. Relation of spontaneous reperfusion in ST-elevation myocardial infarction to more distal coronary culprit narrowings. Am Heart J. 2008; 101:308-10.

10. Rimar D, Crystal E, Battler A, Gottlieb S, Freimark D, Hod H, Boyko V, Mandelzweig L, Behar S, Leor J. Improved prognosis of patients presenting with clinical markers of spontaneous reperfusion during acute myocardial infarction. Heart. 2002; 88:352-6.

11. Thygesen K, Alpert JS, Jaffe AS, Simoons ML, Chaitman BR, White HD, Thygesen K, Alpert JS, White HD, Jaffe AS, Katus HA, Apple FS, Lindahl B, et al, and Writing Group on the Joint ESC/ACCF/AHA/WHF Task Force for the Universal Definition of Myocardial Infarction, and ESC Committee for Practice Guidelines (CPG). Third universal definition of myocardial infarction. Eur Heart J. 2012; 33:2551-67.

12. Breivik EK, Björnsson GA, Skovlund E. A comparison of pain rating scales by sampling from clinical trial data. Clin J Pain. 2000; 16:22-8.

13. Lavi S, Rihal CS, Yang EH, Fassa AA, Elesber A, Lennon RJ, Mathew V, David HR Jr, Lerman A. The effect of drug eluting stents on cardiovascular events in patients with intermediate lesions and borderline fractional flow reserve. Catheter Cardiovasc Interv. 2007; 70:525-31.

14. Sabaté S, Mases A, Guilera N, Canet J, Castillo J, Orrego C, Sabaté A, Fita G, Parramón F, Paniagua P, Rodríguez A, Sabaté M, Martin B, et al, and ANESCARDIOCAT Group. Incidence and predictors of major perioperative adverse cardiac and cerebrovascular events in non-cardiac surgery. Br J Anaesth. 2011; 107:879-90.

15. Jing Li, Elrashidi MY, Flammer AJ, Lennon RJ, Bell MR, Holmes DR, Bresnahan JF, Rihal CS, Lerman LO, Lerman A. Long-term outcomes of fractional flow reserveguided vs. angiography-guided percutaneous coronary intervention in contemporary practice. Eur Heart J. 2013; 34:1375-83.

16. Christenson RH, Ohman EM, Topol EJ, Peck S, Newby LK, Duh SH, Kereiakes DJ, Worley SJ, Alosozana GL, Wall TC, Califf RM. Assessment of coronary reperfusion after thrombolysis with a model combining myoglobin, creatine kinase-MB, and clinical variables. TAMI-7 Study Group. Thrombolysis and Angioplasty in Myocardial Infarction-7. Circulation. 1997; 96:1776-82.
17. Califf RM, O'Neil W, Stack RS, Aronson L, Mark DB, Mantell S, George BS, Candela RJ, Kereiakes DJ, Abbottsmith C, Topol EJ. TAMI Study Group. Failure of simple clinical measurements to predict perfusion status after intravenous thrombolysis. Ann Intern Med. 1988; 108:658-62.

18. Remppis A, Scheffold T, Karrer O, Zehelein J, Hamm C, Grünig E, Bode C, Kübler W, Katus HA. Assessment of reperfusion of the infarct zone after acute myocardial infarction by serial cardiac troponin $\mathrm{T}$ measurements in serum. Br Heart J. 1994; 71:242-8.

19. Antman EM, Anbe DT, Armstrong PW, Bates ER, Green LA, Hand M, Hochman JS, Krumholz HM, Kushner FG, Lamas GA, Mullany CJ, Ornato JP, Pearle DL, et al. ACC/ AHA guidelines for the management of patients with STelevation myocardial infarction: A report of the American College of Cardiology/American Heart Association Task Force on Practice Guidelines (Committee to Revise the 1999 Guidelines for the Management of Patients with Acute Myocardial Infarction). J Am Coll Cardiol. 2004; 44:E1-E211.

20. Akpek M, Kaya MG, Uyarel H, Yarlioglues M, Kalay N, Gunebakmaz O, Dogdu O, Ardic I, Elcik D, Sahin O, Oguzhan A, Ergin A, Gibson CM. The association of serum uric acid levels on coronary flow in patients with STEMI undergoing primary PCI. Atherosclerosis. 2011; 219:334-41.

21. Timmer JR, Ottervanger JP, de Boer MJ, Dambrink JH, Hoorntje JC, Gosselink AT, Suryapranata H, Zijlstra F, van 't Hof AW. Zwolle Myocardial Infarction Study Group. Hyperglycemia is an important predictor of impaired coronary flow before reperfusion therapy in ST-segment elevation myocardial infarction. J Am Coll Cardiol. 2005; 45:999-1002.

22. Ruggiero C, Cherubini A, Ble A, Bos AJ, Maggio M, Dixit VD, Lauretani F, Bandinelli S, Senin U, Ferrucci L. Uric acid and inflammatory markers. Eur Heart J. 2006; 27:1174-81.

23. Kanellis J, Watanabe S, Li JH, Kang DH, Li P, Nakagawa T, Wamsley A, Sheikh-Hamad D, Lan HY, Feng L, Johnson RJ. Uric acid stimulates monocyte chemoattractant protein-1 production in vascular smooth muscle cells via mitogen-activated protein kinase and cyclooxygenase-2. Hypertension. 2003; 416:1287-93.

24. Esposito K, Nappo F, Marfella R, Giugliano G, Giugliano F, Ciotola M, Quagliaro L, Ceriello A, Giugliano D. Inflammatory cytokine concentrations are acutely increased by hyperglycemia in humans: role of oxidative stress. Circulation. 2002; 106:2067-72.

25. Pinto DS, Kirtane AJ, Pride YB, Murphy SA, Sabatine MS, Cannon CP, Gibson CM, and CLARITY-TIMI 28 Investigators. Association of blood glucose with angiographic and clinical outcomes among patients with ST-segment elevation myocardial infarction (from the CLARITYTIMI-28 study). Am J Cardiol. 2008; 101:303-07. 